Revista de
Economila
Contemporâned

\title{
EVIDÊNCIAS DO HIATO DE GÊNERO E PRODUTIVIDADE NA INDÚSTRIA DE TRANSFORMAÇÃO BRASILEIRA
}

\author{
Vinícius Thomaz de Campos ${ }^{a}$ \\ Maria Micheliana da Costa Silva ${ }^{b}$ \\ Leonardo Chaves Borges Cardoso ${ }^{c}$
}

\begin{abstract}
${ }^{a}$ Mestre em Economia Aplicada pelo Programa de Pós-Graduação em Economia Aplicada (PPGEA) da Universidade Federal de Viçosa (UFV). Viçosa, MG, Brasil. ORCID: https://orcid.org/0000-0001-8671-6277.

b Professora adjunta do Departamento de Economia Rural (DER/UFV) e do PPGEA/UFV. Viçosa, MG, Brasil. ORCID: https://orcid.org/0000-0001-6060-4584.
\end{abstract}

${ }^{\text {c }}$ Professor adjunto do DER/UFV e do PPGEA/UFV. Viçosa, MG, Brasil. ORCID: https://orcid.org/00000002-5757-107X.

Recebido em 08 novembro 2019

Aceito em 03 março 2021

RESUMO: Este estudo analisou o hiato de gênero na indústria de transformação brasileira para diferentes quantis da distribuição de salários de homens e mulheres. Para tanto, foram utilizados dados da PNAD e da PIA correspondentes ao período de 2003 a 2015 e aplicou-se a decomposição de Oaxaca-Blinder para diversos quantis das distribuições incondicionais de salários. Foram encontradas evidências de que o nível de produtividade da indústria justifica variações no diferencial de rendimentos do trabalho entre homens e mulheres. Para mulheres que se encontram no topo das distribuições de rendimentos, quanto maior o nível de produtividade da indústria em que estão empregadas, menores serão suas desvantagens salariais; entretanto, nas indústrias menos produtivas, são encontrados menores diferenciais para os indivíduos com menor qualificação e menores rendimentos, além disso, é verificada pouca representatividade feminina em cargos de chefia. Para todos os níveis de produtividade da indústria de transformação brasileira, as mulheres apresentam maior escolaridade do que os homens, mas são nos níveis mais produtivos que essa maior qualificação tem um papel mais relevante para a redução do hiato de gênero.

Correspondência para: Maria Micheliana da Costa Silva

Contato: maria.micheliana@ufv.br 
PALAVRAS-CHAVE: desigualdade salarial; produtividade; indústria de transformação; regressões quantílicas.

CLASSIFICAÇÃO JEL: J16; J71; C31. 


\section{EVIDENCE OF THE GENDER PRODUCTIVITY GAP IN THE BRAZILIAN TRANSFORMATION INDUSTRY}

ABSTRACT: This study analyzed the gender gap in the Brazilian manufacturing industry for different quantiles of male-female wage distribution. For that, we collected data from the PNAD and PIA corresponding to the period between 2003 and 2015 and applied Oaxaca-Blinder decomposition to unconditional quantiles distributions. Our results indicate that the productivity level accounts for male-female wage differentials. Pay disadvantages for women at the top of income distributions will be lower as higher the productivity level of the industry in which they are employed. However, less productive industries show lower differentials for lower-skilled individuals and lower incomes, besides little female representation in managerial positions. Women have higher education level than men for all levels of productivity in the Brazilian manufacturing industry, but such qualification plays a more relevant role in reducing gender gap within the most productive levels.

KEYWORDS: wage inequality; productivity; manufacturing industry; quantile regressions. 


\section{INTRODUÇÃO}

Os diferenciais de salários entre gêneros, fenômeno também conhecido como "hiato de gênero", foi investigado por diversos autores, como Lavinas (2001), Giuberti e MenezesFilho (2005), Bobbitt-Zeher (2007), Alves e Cavenaghi (2013) e Pereira e Oliveira (2017). Todos os citados indicam divergências significativas de rendimentos explicadas pelo gênero, mesmo quando são considerados os diferenciais de experiência e outras variáveis explicadas ligadas à produtividade. Tal fato não condiz com a teoria do capital humano, sustentada por Becker (1962), que aponta que os rendimentos do trabalho de um indivíduo são determinados apenas por suas características produtivas.

Remunerar os trabalhadores por fatores não relacionados a sua produtividade, além de ser entendido como algo, no mínimo, injusto, também é ineficiente do ponto de vista econômico, visto que empresas lideradas por mulheres têm melhor desempenho em relação às lideradas por homens (FLABBI et al., 2019). A ideia é que empresas com diversidade de gênero nos cargos de chefia estariam fazendo um melhor aproveitamento dos talentos, uma vez que não restringem cargos de chefia aos homens. A preocupação em relação aos diferenciais de salário entre os gêneros é um dos Objetivos de Desenvolvimento do Milênio, definidos pela Organização das Nações Unidas (ONU), descrito como "promover a igualdade entre sexos e a autonomia das mulheres".

No Brasil, entre aqueles indivíduos que estão no mercado de trabalho formal, as mulheres têm maior escolaridade, somando $52 \%$ da força de trabalho com ensino superior incompleto e $59 \%$ da com ensino superior completo (BRASIL, 2018). Sendo maioria nos dois estratos de maior escolaridade, espera-se uma maior representatividade feminina em ocupações que exigem trabalhadores mais qualificados e, consequentemente, com maiores rendimentos. Apesar disso, as mulheres têm salários médios menores do que os homens em todos os níveis de escolaridade apresentados na RAIS (BRASIL, 2018). Essas diferenças são ainda maiores para os níveis de escolaridade mais elevados, de forma que a maior diferença verificada ocorre para indivíduos com ensino superior completo. Entre os trabalhadores com ensino superior completo, mulheres ganham $63,7 \%$ do salário médio dos homens (salários médios de $\mathrm{R} \$ 4.803,77$ para as mulheres e de $\mathrm{R} \$ 7.537,27$ para os homens, segundo dados de dezembro de 2016 na RAIS).

\footnotetext{
1 As metas definidas pela Cúpula do Milênio da ONU são: erradicar a pobreza e a fome; atingir o ensino básico universal; promover a igualdade entre gêneros e a autonomia da mulher; reduzir a mortalidade na infância; melhorar a saúde materna; combater a aids, a malária e outras doenças; garantir a sustentabilidade ambiental; estabelecer uma parceria mundial para o desenvolvimento, podendo ser vistos em: https://www.br.undp.org/content/brazil/pt/home/sustainable-development-goals.html.
} 
Uma vez que os diferenciais de ganho entre os gêneros podem ser explicados também pelos diferenciais de participação dos gêneros em alguns setores da economia, este trabalho foca especificamente na indústria de transformação, um setor no qual a participação dos homens é de 68\% (BRASIL, 2018). Desta forma, será possível tanto controlar características específicas da indústria de transformação, como entender dinâmicas particulares que explicam as diferenças de ganho neste setor específico.

Nesse sentido, este artigo tenta entender como o hiato de gênero apresenta-se nos diferentes setores e subsetores da indústria de transformação e como o nível da produtividade $^{2}$ encontrado nesses subsetores ${ }^{3}$ se relaciona com as desigualdades de gênero. Além de verificar o hiato de rendimentos de gênero na média salarial, também é possível verificar o comportamento desse fenômeno ao longo da distribuição de rendimentos por meio de análise quantílica. Esse tipo de abordagem mostra-se interessante por viabilizar a análise dos determinantes desse hiato para diferentes quantis da distribuição de salários, permitindo visualizar a evolução das desigualdades de rendimentos para diferentes níveis de renda e analisar os efeitos de variáveis explicativas para cada um desses níveis.

O estudo é apresentado em cinco seções, incluindo essa introdução. A próxima seção se dedica a fazer a revisão da literatura sobre hiato de gênero, seguida da seção que traz a metodologia usada para calcular o nível de produtividade dos subsetores e apresenta a base de dados utilizada. Em seguida, apresentam-se os principais resultados e considerações finais do estudo.

\section{REVISÃO DA LITERATURA}

Uma das explicações para os diferenciais salariais em relação a gênero é a baixa participação feminina em ocupações ligadas às ciências, engenharias e computação. As ocupações STEM (do inglês: Science, Techonology, Engineering and Math) tendem a ter melhores salários do que a média. Barth et al. (2017) mostram que a presença de engenheiros e cientistas eleva a produtividade das firmas, aumentando não só a remuneração destes, mas também dos outros trabalhadores que se encontram nessas firmas. Se as mulheres têm participação relativamente menor nestas empresas, esta pode ser uma explicação para a desigualdade de gênero nos salários. Nos Estados Unidos, por exemplo, as mulheres compõem menos de $25 \%$ dos trabalhadores nas ocupações

\footnotetext{
2 O cálculo da produtividade total dos fatores é apresentado na terceira seção.

3 A relação dos subsetores da indústria de transformação encontra-se no Anexo 1.
} 
STEM, ainda que representem aproximadamente $50 \%$ do total de trabalhadores do país (BEEDE et al., 2011).

Conforme indicado por Card, Cardoso e Kline (2013), outro fator relevante na formação do hiato de gênero, especialmente no setor em destaque, é o poder de barganha dos trabalhadores. Usando dados para Portugal, os autores identificam que, nas firmas em que há predominância de funcionários do sexo masculino, os trabalhadores têm maior poder de negociação de prêmios salariais do que nas firmas em que há predominância de funcionárias.

A desigualdade de gênero também tem ligações com dificuldades enfrentadas pelas mulheres para ascender na carreira dentro da própria empresa, fenômeno conhecido como "teto de vidro" (POWELL; BUTTERFIELD, 2015). Coelho, Fernandes e Foguel (2010), investigando diferenciais de gênero relativos às promoções nas grandes indústrias brasileiras, corroboram a hipótese de que mulheres não têm as mesmas oportunidades de ascensão que homens dentro da indústria brasileira. ${ }^{4}$

Esta baixa representatividade do gênero feminino nos postos mais elevados das empresas está relacionada com uma menor produtividade das empresas. Utilizando dados a nível de firma para os EUA, Flabbi et al. (2019) encontram evidências de que uma maior participação de mulheres em cargos de chefia diminui o hiato de gênero no topo da distribuição de rendimentos e aumenta o desempenho das firmas em relação à produtividade total dos fatores, vendas por trabalhador e valor adicionado por trabalhador.

Blau e Kahn (2017) analisam a evolução do hiato de rendimentos de gênero para os EUA durante os anos de 1980 e 2011 e, utilizando uma abordagem quantílica, verificam que o hiato de gênero diminui ao longo da distribuição de rendimentos no período analisado, ainda que essa redução ocorra de forma mais lenta no topo da distribuição. O mesmo comportamento foi encontrado em Meireles (2014) para o mercado brasileiro: as diferenças de rendimentos por gênero se reduzem mais lentamente no topo da distribuição de rendimentos.

No Brasil, poucos trabalhos utilizam a abordagem quantílica para a análise dos diferenciais de rendimentos por gênero, sendo que tais estudos não verificaram a importância do nível de produtividade nem analisaram setores específicos. ${ }^{5}$ Devido aos diferentes níveis de produtividade dos setores da indústria de transformação, uma

4 O fenômeno do teto de vidro é testado em diversos trabalhos outros trabalhos, uma extensiva pode ser encontrada em Powell e Butterfield (2015).

5 Essa abordagem foi aplicada por Bartalotti (2007), que trata da discriminação salarial de raça e gênero para o Brasil, além de Meireles (2014), que analisa a evolução do hiato de gênero no Brasil, a partir de dados da PNAD/IBGE, entre os anos de 1976 e 2009. 
abordagem quantílica incondicional pode trazer novas evidências de como esse hiato se comporta ao longo da distribuição de rendimentos salariais. Será possível verificar também se esses diferenciais por gênero seguem uma tendência de redução mais lenta nos níveis mais altos de rendimentos, além de possibilitar a análise da relação de hiato de gênero e produtividade da indústria para diferentes faixas salariais.

\section{METODOLOGIA}

Nesta seção, inicialmente é apresentada a formulação do cálculo da fração de receita por pessoa, proxy para produtividade dos subsetores industriais, medida usada em Flabbi et al. (2019). Por meio dessa medida, buscou-se compreender o quanto é produzido por trabalhador em cada subsetor da indústria de transformação. Dividindo a receita total de vendas de cada subsetor pelo seu respectivo número de trabalhadores empregados, tem-se a receita líquida de vendas para cada trabalhador. Considerou-se que, quanto maior a receita por trabalhador de uma determinada indústria, maior a sua produtividade. Em seguida, tem-se a descrição das construções das demais variáveis e estratégia empírica empregadas.

Para alcançar os objetivos propostos, a análise utilizou dados do período de 2003 a $2015,{ }^{6}$ com cross sections independentes empilhadas, em duas etapas distintas. A primeira estima os rendimentos dos grupos analisados por quantis, por meio da Recentered Influence Function Regression (RIF Regression), proposta por Firpo, Fortin e Lemieux (2009). A segunda realiza uma decomposição do diferencial de rendimentos dos grupos por meio de uma generalização do método de Oaxaca-Blinder.

No modelo proposto, estratificou-se os níveis de produtividade, analisando o hiato de gênero para cada estrato de produtividade separadamente. As estratificações foram formadas da seguinte forma: os setores que estão no primeiro quartil da distribuição das receitas por pessoal foram considerados de baixa produtividade, os segundo e terceiro quartis foram considerados de nível de produtividade intermediária, e o último quartil foi considerado de alta.

A análise foi realizada com a finalidade de compreender a relação entre produtividade e o gap de gênero na indústria de transformação. Buscou-se entender como o nível de produtividade afeta os rendimentos do trabalho de homens e mulheres e qual efeito ele

6 Exceto para o ano de 2010, pois, nesse ano, foram coletados dados para o Censo Demográfico em vez da PNAD/IBGE. 
tem sobre o hiato existente entre seus rendimentos. As unidades estudadas foram os subsetores industriais classificados por dois dígitos pela CNAE (IBGE, 2018a). ${ }^{7}$

\subsection{BASE DE DADOS E VARIÁVEIS}

Seguindo Flabbi et al. (2019), calcula-se a para produtividade ${ }^{8}$, medida entre a razão entre o total de receitas líquidas de vendas e o total de pessoas empregadas no subsetor $h$, pela seguinte equação:

$$
R P P_{h}=\frac{R T V_{h}}{P_{h}}
$$

Em (1): $R P P_{h}$ é a receita total de vendas por pessoa do subsetor $h, R T V_{h}$ é a receita total de vendas de do subsetor h e $P_{h}$ é o total do pessoal empregado no subsetor $h$.

Para construir esta medida de produtividade, recorre-se aos dados fornecidos pela Pesquisa Industrial Anual (IBGE, 2018b), referentes à receita líquida de vendas e pessoal ocupado em empresas industriais com cinco ou mais trabalhadores para subsetor da indústria de transformação de acordo com a Classificação Nacional de Atividades Econômicas (CNAE). Dessa forma, foi obtido o total receitas líquidas de vendas por pessoa de cada subsetor analisado entre os anos de 2003 e 2015 (exceto 2010). As receitas líquidas de vendas totais foram deflacionadas com a utilização do INPC, sendo o ano de 2003 utilizado como base para o cálculo.

Quanto às variáveis que caracterizam os indivíduos, estas foram criadas com base nos dados da Pesquisa Nacional de Amostra de Domicílios (IBGE, 2018c). Foram considerados indivíduos com idade entre 18 e 60 anos que estavam empregados em atividade remunerada na semana de referência da pesquisa e exercendo sua atividade principal na indústria de transformação. Também foram retirados indivíduos com rendimentos não declarados e aqueles com ocupação mal definida. Com isso, a amostra final contém 188.256 observações.

A compatibilização das bases foi realizada por meio dos subsetores da indústria de transformação especificados na PIA pela CNAE 1.0, entre 2003 e 2006, e pela CNAE

\footnotetext{
7 A Classificação Nacional de Atividades Econômicas - CNAE é a classificação oficialmente adotada pelo IBGE para ordenar as atividades econômicas do Brasil. Ela possui algumas versões e a sua versão mais recente é a CNAE 2.0, que foi adotada a partir de 2007. É possível compatibilizar a atual versão com as versões anteriores que foram adotadas no período de 1994 a 2007.

8 Não foram utilizadas outras medidas de produtividade, como o Índice de Malmqvist e o Total Factor Productivity (TFP), devido à restrição ao acesso de dados à nível de firma das indústrias de transformação brasileiras.
} 
2.0, entre 2007 e 2015. Por parte dos dados da PNAD, os subsetores são apresentados por meio da variável "código de ocupação da atividade principal”, cujas informações foram compatibilizadas com a CNAE 1.0.

Como variável de interesse, considerou-se o total de rendimentos da atividade principal, convertidos em valores por hora trabalhada (em logaritmo). Além da variável que representa a produtividade $(R P P)$, inclui-se como variáveis de controle a escolaridade $(E s c)$, medida em anos de estudo, além da variável de experiência (Exp), que foi construída subtraindo da idade do indivíduo o número de anos de estudo mais seis, idade em que geralmente é iniciada a vida escolar. Considera-se também uma variável que indica se o indivíduo é sindicalizado (sind), assim como para indicar se é residente em áreas urbanas ( $r u r b)$.

Também foram incluídas dummies relativas à ocupação (dir, ger, cienc e tec), que são importantes para a análise por apresentar os retornos gerados, tanto para homens, quanto para mulheres, em diferentes níveis de ocupação. Assim, torna-se interessante a comparação dos retornos para cargos de alto nível (diretores e gerentes) com os demais cargos do setor de transformação, pois comumente as mulheres apresentam grande desvantagem de rendimentos no topo da distribuição de rendimentos (FLABBI et al., 2019). Nos demais cargos considerados, tem-se os ligados às ciências e artes (cienc), que englobam pesquisadores, engenheiros, desenhistas industriais, entre outras ocupações de nível superior, além dos cargos técnicos (tec), que consideram inspetores, desenhistas técnicos e profissionais de nível técnico em geral. Estas variáveis foram criadas com base na própria classificação de ocupações fornecida pela PNAD (IBGE, 2018c). Na Tabela 1, apresentam-se as principais estatísticas de todas as variáveis. Em seguida, apresentam-se os principais resultados e considerações finais do estudo.

Tabela 1 - Estatísticas descritivas das variáveis dependente e independentes

\begin{tabular}{ccc}
\hline Variáveis & Média & Desvio-padrão \\
\hline Salário/hora total $($ em log $)$ & 1,31 & 2,27 \\
Salário/hora Homens $($ em log) & 1,41 & 2,29 \\
Salário/hora Mulheres $($ em log) & 1,08 & 2,21 \\
Esc & 9,562 & 3,729 \\
Exp & 17,844 & 12,080 \\
RPP & 142,761 & 128,950 \\
Sind & 0,240 & 0,427 \\
Rurb & 0,933 & 0,250 \\
Dir & 0,003 & 0,058 \\
Ger & 0,037 & 0,190 \\
Cienc & 0,037 & 0,190 \\
Tec & 0,082 & 0,275 \\
\hline
\end{tabular}




\subsection{DECOMPOSIÇÃO CONTRAFACTUAL E REGRESSÃO QUANTÍLICA INCONDICIONAL}

Diferenças nos rendimentos salariais entre grupos podem ser devidas a diferenças de experiência e estoque educacional, no entanto, segundo Blinder (1973), mesmo que tais grupos tenham características produtivas similares, é possível que um grupo tenha menor retorno salarial menor do que o outro devido à discriminação e outros fatores que dificultam o acesso a ocupações com maiores ganhos salariais. O procedimento de Oaxaca-Blinder é usual para separar tais componentes da desigualdade (efeito composição e efeito estrutural), além de permitir verificar a contribuição de cada variável explicativa nessa decomposição (FIRPO; FORTIN; LEMIEUX, 2018). A decomposição pode ser dada por (BLINDER, 1973):

$$
\ln \bar{w}_{i H}-\ln \bar{w}_{i L}=\left(\bar{X}_{i H}-\bar{X}_{i F}\right) \beta_{H}+\left(\beta_{H}-\beta_{L}\right) \bar{X}_{i F}
$$

Em (2), $\bar{w}_{g}$ é o salário médio para o grupo $g=\{H, L\}$, sendo que o subscrito $H$ indica os indivíduos com maior nível salarial e $L$ com menor nível salarial, no caso, indivíduos do sexo masculino e do sexo feminino, respectivamente); $\bar{X}_{i g}$ é um vetor de características observadas do i-ésimo indivíduo, pertencente ao grupo $g$ e $\beta_{g}$ é um vetor com os respectivos coeficientes.

Com isso, explica-se as diferenças salariais tanto por atributos produtivos quanto por características que não estão relacionadas à produtividade. $\left(\bar{X}_{i H}-\bar{X}_{i F}\right) \beta_{H}$ representa os efeitos de composição, que explicam a diferença de rendimentos relacionada às características produtivas observáveis de cada grupo. Já a parcela $\left(\beta_{H}-\beta_{L}\right) \bar{X}_{i F}$ explica a diferença de rendimentos devido a fatores não observáveis (efeito estrutural), que podem sofrer a influência de características individuais de homens e mulheres como aversão a risco e poder de barganha e representam as diferenças resultantes de discriminação contra o sexo feminino.

A decomposição em (2) pode ser estimada por meio do método de Mínimos Quadrados Ordinários (MQO), que permite a obtenção do efeito de um aumento da variável explicativa sobre a média dos rendimentos dos grupos de interesse. Alternativamente, a análise das diferenças salariais pode ser feita além de uma simples comparação das médias. De acordo com Firpo, Fortin e Lemieux (2018), tem-se crescido o interesse nos impactos distributivos das variáveis que explicam a existência de desigualdades entre grupos, focando-se nas mudanças ou diferenças ao longo das distribuições salariais. No entanto, segundo Angrist e Pischke (2008), de acordo com a Lei das Expectativas Iteradas, os coeficientes encontrados por MQO são os mesmos para uma estimação condicional e incondicional, como se faz necessário em uma decomposição de médias incondicionais. Isso não se aplica a uma análise nos quantis da distribuição de interesse. Ao contrário da média condicional, os impactos sobre quantis condicionais não são os mesmos sobre suas contrapartes 
incondicionais. Especificamente para a decomposição em (2), é necessário encontrar os efeitos sobre os quantis marginais.

Nesse sentido, Firpo, Fortin e Lemieux (2009) sugerem um método de regressão quantílica incondicional, por meio de uma Recentered Influence Function Regression (RIF Regression). Além de dar uma caracterização mais detalhada do impacto das variáveis, ao longo da distribuição da variável de interesse, a regressão quantílica é mais robusta a outliers e erros não normais do que à estimação pela média (ANGRIST; PISCHKE, 2008). Quanto ao uso da RIF para a estimação da regressão quantílica incondicional, Firpo, Fortin e Lemieux (2009) citam como vantagem a facilidade de obter estimativas robustas para cada quantil de interesse, permitindo encontrar os efeitos parciais de cada quantil da distribuição incondicional. Outra vantagem do método é a possibilidade de generalizar a análise de decomposição de Oaxaca-Blinder em (2).

A RIF usa um conceito de influence function (IF) que pode ser usado para quantis e outros tipos de distribuição estatística. É possível reescrever o modelo quantílico nos moldes da decomposição em (2), substituindo o coeficiente estimado por MQO pelo coeficiente da densidade de Kernel obtido com a regressão quantílica (FIRPO; FORTIN; LEMIEUX, 2009, 2018):

$$
\widehat{R^{\tau}}=\left(\bar{X}_{i H}-\bar{X}_{i L}\right) \widehat{\gamma_{H}, \tau}+\left(\widehat{\gamma_{H, \tau}}-\widehat{\gamma_{L, \tau}}\right) \bar{X}_{i L}
$$

em que $\widehat{\mathrm{R}^{\tau}}$ é a diferença total dos grupos no $\tau$-ésimo quantil estimado; $\widehat{\gamma_{\mathrm{g}, \tau}}$ é um vetor com os respectivos coeficientes, no $\tau$-ésimo quantil incondicional.

\subsection{ESTRATÉGIA EMPÍRICA}

Para verificar o efeito da produtividade do setor de transformação sobre as desigualdades salariais, parte-se da especificação em (4), que traz a para produtividade de forma contínua, calculada para cada subsetor $h$ no período $t$, conforme apresentado na subseção 2.1. Procede-se às estimações por sexo de forma separada, para, então, realizar as decomposições de acordo com os resultados de cada grupo. Para o $i$-ésimo indivíduo, participante do grupo $g$, estima-se:

$$
l n w_{i g t}=X_{i g t} \beta_{g}+\gamma R P P_{h t}+\delta_{t}+\varepsilon_{i g t}
$$

Em (3), $w_{i g t}$ é o rendimento do i-ésimo indivíduo, pertencente ao g-ésimo grupo (homem ou mulher), no período t; $X_{i g t}$ contém as características sociodemográficas (anos de estudo, experiência e seu termo quadrático, dummies que indicam se o indivíduo é sindicalizado, se mora em áreas urbanas, além de dummies de ocupação, para indicar se o indivíduo é diretor, gerente, profissional de ciências e artes ou se é técnico); $R P P_{h t}$ 
é a variável que representa a produtividade do subsetor $h ; \delta_{t}$ capta os efeitos dos períodos analisados e , em que se pressupõe $\varepsilon_{i g t} \sim\left(0, \sigma^{2}\right)$.

Além da estimação do efeito da produtividade do subsetor, para captar a influência por nível de produtividade (alta, média e baixa), estima-se a especificação em (4), considerando dummies para os níveis de produtividade. Estas dummies foram construídas considerando os quartis da distribuição da medida de produtividade, sendo que o nível alto considera o subsetor pertencente aos $25 \%$ mais produtivos. O nível intermediário considera os subsetores que estão entre os $25 \%$ e $75 \%$ mais produtivos. No nível mais baixo estão os $25 \%$ menos produtivos, considerados como categoria base.

Por fim, para verificar se há efeitos heterogêneos entre os níveis de produtividade, partindo desta estratificação, estima-se as equações mincerianas para cada nível de produtividade separadamente. Assim, nesta terceira especificação, não são acrescentadas variáveis relativas à produtividade, que é utilizada apenas para separar os níveis. Com isso, possibilita-se a mensuração dos diferenciais de rendimentos entre os grupos analisados para os diferentes níveis de produtividade.

\section{RESULTADOS E DISCUSSÃO}

Antes de mostrar o hiato de gênero na indústria de transformação brasileira e como o nível da produtividade de seus subsetores relaciona-se com as desigualdades de gênero, nessa seção são apresentadas as informações descritivas que caracterizam os grupos e os indivíduos estudados de acordo com ganhos médios por grupo, alocação dos trabalhadores nos diferentes ramos da indústria de transformação e como cada gênero está distribuído entre os diferentes tipos de ocupação analisados. Após essa caracterização, são apresentados os resultados obtidos pela estimação das regressões quantílicas incondicionais das equações mincerianas para cada grupo e, por fim, os resultados da decomposição dos diferenciais de rendimentos encontrados para toda a amostra e por níveis de produtividade.

\subsection{HOMENS, MULHERES E PRODUTIVIDADE NA INDÚSTRIA DE TRANSFORMAÇÃO}

O índice de produtividade é originado pela variável $R P P_{h}$, razão das receitas totais líquidas de vendas em mil reais pelo pessoal empregado em cada indústria. As características dessa variável são apresentadas pela Tabela 2, de acordo com o nível de produtividade. A tabela mostra que, quanto mais elevado o nível de produtividade, maior a dispersão do índice. Como apresentado anteriormente, os níveis são divididos em quartis de acordo com a frequência da variável $R P P h$. 
Tabela 2 - Características do índice de produtividade por nível, total de receitas líquidas de vendas anual (em mil reais) dividido pelo número de trabalhadores

\begin{tabular}{ccccc}
\hline \multirow{2}{*}{ Nível de Produtividade } & \multicolumn{4}{c}{ Índice de Produtividade } \\
\cline { 2 - 5 } & Média & Desvio padrão & Min. & Máx. \\
\hline Alta & 319,4 & 148,4 & 158,5 & 954,7 \\
Média & 109,0 & 32,2 & 56,1 & 154,8 \\
Baixa & 40,8 & 9,6 & 24,6 & 55,0 \\
\hline
\end{tabular}

Fonte: Elaboração própria.

A Tabela 3 traz as indústrias analisadas, a classificação por nível de produtividade e seus respectivos índices de produtividade. A maior parte dos setores encontra-se no nível de média produtividade, o que é esperado devido aos intervalos definidos para a estratificação. O estrato de baixa produtividade é aquele que apresenta o menor número de setores, entretanto, esse estrato apresenta número de trabalhadores equivalente ao estrato de alta produtividade, o que será apresentado nas próximas seções.

\section{Tabela 3 - Subsetores da indústria de transformação e} seus respectivos índices de produtividade

\begin{tabular}{|c|c|c|}
\hline Indústria & CNAE & $\begin{array}{c}\text { Índice de } \\
\text { produtividade }\end{array}$ \\
\hline \multicolumn{3}{|l|}{ Alta produtividade } \\
\hline Fabricação de coque, de produtos derivados de petróleo e de biocombustíveis & 23 & 764,4 \\
\hline Fabricação de Fumo & 16 & 374,7 \\
\hline Metalurgia & 27 & 364,4 \\
\hline Fabricação de produtos químicos & 24 & 360,4 \\
\hline Fabricação de veículos automotores, reboques e carrocerias & 34 & 272,2 \\
\hline Fabricação de máquinas para escritórios e equipamentos de informática & 30 & 267,4 \\
\hline Fabricação de outros equipamentos de transporte & 35 & 213,2 \\
\hline Fabricação de celulose, papel e produtos de papel & 21 & 190,5 \\
\hline \multicolumn{3}{|l|}{ Média produtividade } \\
\hline Fabricação de alimentos e bebidas & 15 & 145,5 \\
\hline Fabricação de máquinas, aparelhos e materiais elétricos & 31 & 143,4 \\
\hline Fabricação de máquinas e equipamentos & 29 & 140,3 \\
\hline Fabricação de produtos de borracha e produtos de plásticos & 25 & 109,3 \\
\hline Fabricação de produtos minerais não metálicos & 26 & 86,2 \\
\hline Impressão e reprodução de gravações & 22 & 85,5 \\
\hline Fabricação de produtos de metal, exceto máquinas e equipamentos & 28 & 84,2 \\
\hline Fabricação de produtos têxteis & 17 & 71 \\
\hline Fabricação de móveis e indústrias diversas & 36 & 55,6 \\
\hline
\end{tabular}


Tabela 3 - Subsetores da indústria de transformação e seus respectivos índices de produtividade (CONTINUAÇÃO)

\begin{tabular}{lcc}
\hline \multicolumn{1}{c}{ Indústria } & CNAE & $\begin{array}{c}\text { Índice de } \\
\text { produtividade }\end{array}$ \\
\hline Baixa produtividade & & \\
\hline $\begin{array}{l}\text { Fabricação de produtos de madeira } \\
\begin{array}{l}\text { Preparação de couros e fabricação de artigos de couro, artigos para viagem } \\
\text { e calçados }\end{array}\end{array}$ & 19 & 45,4 \\
Confecção de artigos de vestuário e acessórios & 18 & 30,6 \\
\hline
\end{tabular}

Fonte: Elaboração própria.

A alocação dos trabalhadores e as médias de anos de escolaridade para homens e mulheres para toda a amostra e distribuídas entre os setores de acordo com seus níveis de produtividade são apresentadas na Tabela 4 .

\section{Tabela 4 - Participação dos trabalhadores por sexo e nível} de produtividade para os anos de 2003 e 2015

\begin{tabular}{ccccc}
\hline & \multicolumn{2}{c}{ Participação } & \multicolumn{2}{c}{ Média de Anos de Estudo } \\
\cline { 2 - 5 } & $\mathbf{2 0 0 3}$ & $\mathbf{2 0 1 5}$ & $\mathbf{2 0 0 3}$ & $\mathbf{2 0 1 5}$ \\
\hline Alta Produtividade & & & 10,03 & 10,86 \\
\hline Homens & $2424(80,56 \%)$ & $4041(74,70 \%)$ & 11,34 & 11,24 \\
Mulheres & $585(19,44 \%)$ & $1369(25,30 \%)$ & 8,53 & 10,02 \\
\hline Média Produtividade & & & 9,57 & 11,30 \\
\hline Homens & $5399(76,94 \%)$ & $4089(77,37 \%)$ & 9,85 \\
Mulheres & $1618(23,06 \%)$ & $1196(22,63 \%)$ & 7,52 & 9,89 \\
\hline Baixa Produtividade & & & 8,36 & 10,39 \\
\hline Homens & $2558(54,63 \%)$ & $707(35,64 \%)$ & 10,81 \\
Mulheres & $2124(45,37 \%)$ & $1277(64,36 \%)$ & 8,63 & \\
\hline Indústria de Transformação (Total) & & 9,22 & \\
\hline Homens & $10381(70,58 \%)$ & $8837(69,70 \%)$ & & \\
Mulheres & $4327(29,42 \%)$ & $3842(30,30 \%)$ & 12676 & \\
\hline Total & 21451 & &
\end{tabular}

Fonte: Elaboração própria.

Com base nas informações fornecidas pela Tabela 4, pode-se observar que a representatividade feminina apresenta uma relação inversa com o nível de produtividade, ou seja, quanto maior o nível de produtividade, menor a sua participação, mesmo com média de anos de estudo superior ao dos homens, em média. Nos setores de alta produtividade a participação feminina variou de 19,44\% para 25,30\% de 2003 para 2015 , enquanto a variação foi de 23,06\% para 22,63\% nos setores de média produtividade no mesmo período. Já para os setores que apresentam baixa produtividade, as mulheres 
representam pouco menos que metade dos trabalhadores, 45,37\% em 2003, com crescimento significativo, alcançando 64,36\% em 2015. Isso demonstra uma participação desproporcional das mulheres em setores de baixa produtividade em relação à participação em setores mais produtivos da indústria de transformação.

Um padrão encontrado para toda a indústria de transformação, independentemente do nível de produtividade, é a média de anos de estudo. Para todos os três estratos, as mulheres apresentam média de anos de estudo maior que os homens. A média de anos de estudos cresce tanto para homens quanto para mulheres, conforme os níveis de produtividade aumentam. Nos estratos de média e alta produtividade a vantagem feminina em termos de escolaridade é significativamente maior do que no estrato de baixa produtividade. Tal fato pode demonstrar uma maior exigência para o acesso das mulheres em subsetores com maior produtividade.

Quanto às composições dos diferentes tipos de ocupação na indústria de transformação, diretores, gerentes, profissionais das ciências e das artes, profissionais técnicos e operários (Tabela 5), pode-se verificar que, independentemente do nível de produtividade, as mulheres têm acesso limitado aos cargos de chefia. Ao longo de toda a distribuição, as mulheres têm acesso limitado aos cargos de chefia (diretoria e gerência) nos subsetores com maiores níveis de produtividade, enquanto a participação aumentou nas demais ocupações.

\section{Tabela 5 - Participação por gênero nos tipos de ocupação, de acordo com estrato de produtividade, para os anos de 2003 a 2015}

\begin{tabular}{|c|c|c|c|c|c|c|c|c|}
\hline & \multicolumn{2}{|c|}{ Baixa Produtividade } & \multicolumn{2}{|c|}{ Média Produtividade } & \multicolumn{2}{|c|}{ Alta Produtividade } & \multicolumn{2}{|c|}{ Total } \\
\hline & 2003 & 2015 & 2003 & 2015 & 2003 & 2015 & 2003 & 2015 \\
\hline \multicolumn{9}{|c|}{ Diretores e Diretoras } \\
\hline Homens & $100 \%$ & $100 \%$ & $81 \%$ & $85 \%$ & $71 \%$ & $92 \%$ & $81 \%$ & $89 \%$ \\
\hline Mulheres & $0 \%$ & $0 \%$ & $19 \%$ & $15 \%$ & $29 \%$ & $8 \%$ & $19 \%$ & $11 \%$ \\
\hline \multicolumn{9}{|l|}{ Gerentes } \\
\hline Homens & $56 \%$ & $49 \%$ & $77 \%$ & $62 \%$ & $76 \%$ & $78 \%$ & $73 \%$ & $68 \%$ \\
\hline Mulheres & $44 \%$ & $51 \%$ & $23 \%$ & $38 \%$ & $24 \%$ & $22 \%$ & $27 \%$ & $32 \%$ \\
\hline \multicolumn{9}{|c|}{ Profissionais de Ciências e Artes } \\
\hline Homens & $60 \%$ & $59 \%$ & $62 \%$ & $56 \%$ & $65 \%$ & $63 \%$ & $63 \%$ & $60 \%$ \\
\hline Mulheres & $40 \%$ & $41 \%$ & $38 \%$ & $44 \%$ & $35 \%$ & $37 \%$ & $37 \%$ & $40 \%$ \\
\hline \multicolumn{9}{|c|}{ Profissionais Técnicos } \\
\hline Homens & $53 \%$ & $46 \%$ & $81 \%$ & $75 \%$ & $79 \%$ & $78 \%$ & $77 \%$ & $73 \%$ \\
\hline Mulheres & $41 \%$ & $54 \%$ & $19 \%$ & $25 \%$ & $21 \%$ & $22 \%$ & $23 \%$ & $27 \%$ \\
\hline \multicolumn{9}{|l|}{ Operários } \\
\hline Homens & $54 \%$ & $34 \%$ & $77 \%$ & $80 \%$ & $82 \%$ & $75 \%$ & $70 \%$ & $70 \%$ \\
\hline Mulheres & $46 \%$ & $66 \%$ & $23 \%$ & $20 \%$ & $18 \%$ & $25 \%$ & $30 \%$ & $30 \%$ \\
\hline
\end{tabular}

Fonte: Elaboração própria. 
A Tabela 5 mostra que, independentemente do nível de produtividade, as mulheres têm acesso limitado aos cargos de chefia. Ao longo de toda a distribuição, os homens são maioria em todos os tipos de cargos, entretanto, a participação das mulheres é pouco representativa nos cargos de diretoras e gerentes. Para o ano de 2003, elas representam $37 \%$ dos profissionais de ciências e artes, apenas $27 \%$ dos gerentes e 19\% dos diretores, enquanto, para 2015, representam 40\%, 32\% e 11\%, respectivamente. Essa queda abrupta da proporção de mulheres nos cargos ligados às ciências e artes para os cargos de gerentes e diretores pode sinalizar uma dificuldade de pessoas do gênero feminino para alcançarem cargos de chefia, evidenciando a existência do fenômeno "teto de vidro" na indústria de transformação brasileira.

O Gráfico 1 apresenta as médias dos rendimentos separados por sexo e nível de produtividade. De acordo com o aumento da produtividade, maiores os rendimentos tanto para homens quanto para mulheres. A maior diferença absoluta encontra-se no nível médio de produtividade e a menor diferença relativa encontra-se no nível de alta produtividade, o que demonstra uma vantagem para as mulheres que estão nos setores de alta produtividade. Nesse caso, sair de um nível mais baixo de produtividade, seja de baixa ou média produtividade, e migrar para indústrias de alta produtividade gera ganhos nos rendimentos absolutos e relativos das mulheres. Entretanto, quando a mulher sai de uma indústria de baixa produtividade e migra para uma indústria de média produtividade, ela será beneficiada pelos maiores ganhos absolutos e terá desvantagens nos ganhos relativos. Logo, a simples mudança para uma indústria de maior produtividade não garantirá rendimentos relativos maiores para as mulheres, sendo um fator que depende de para qual nível de produtividade essa mulher está migrando.

\section{Gráfico 1 - Rendimentos médios por sexo e nível de produtividade}

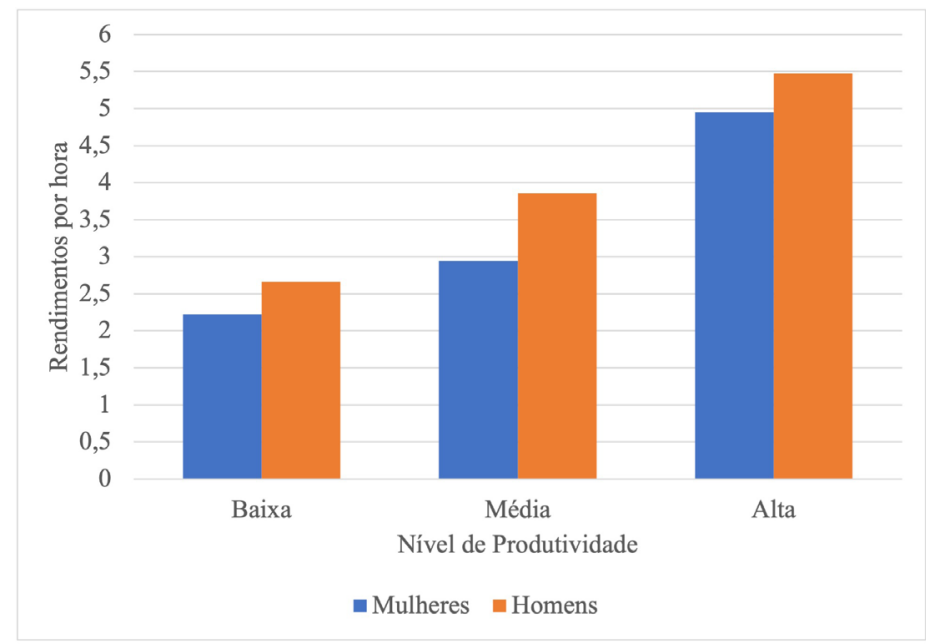




\subsection{DECOMPOSIÇÃO DO DIFERENCIAL DE SALÁRIOS ENTRE HOMENS E MULHERES POR QUANTIS}

A partir de uma análise quantílica, pode-se compreender como o hiato de gênero apresenta-se além da média salarial. A sua decomposição contrafactual é importante para que seja possível verificar como esse hiato é formado e por quais fatores ele pode ser explicado.

A Tabela 6 apresenta os efeitos da variável que mede a produtividade dos subsetores, além dos efeitos por nível de produtividade (alta e média, tendo o nível baixo como base de comparação). Nas duas primeiras colunas, analisa-se apenas o efeito da produtividade no hiato de gênero ao longo dos quantis. Verifica-se que, dado o sinal negativo na parte explicada (efeito de composição) a produtividade das indústrias gera maiores rendimentos para mulheres pois, em todos os quantis analisados, as mulheres conseguem se alocar em indústrias mais produtivas, o que gera uma vantagem para elas em relação aos homens quando encontram-se nos mesmos quantis. Por outro lado, como a parte não explicada da decomposição apresentou sinal positivo, pode-se dizer que o retorno da produtividade é maior para o homem. Isso indica que, quando um homem sai de um subsetor com um nível de produtividade menor para um de nível maior, ele recebe salário maior do que uma mulher receberia. Os efeitos não explicados mostram que o nível de produtividade pode ser mais benéfico aos homens, contribuindo com o hiato de gênero. Adicionando-se às conclusões de Blau e Kahn (2017), que mostram a importância da ocupação e indústria na explicação do hiato de gênero, pode-se verificar também a contribuição da produtividade sobre os salários pagos nos subsetores de uma indústria.

\section{Tabela 6 - Efeitos da variável de produtividade e das dummies de nível de produtividade}

\begin{tabular}{ccccccc}
\hline & \multicolumn{2}{c}{ Produtividade } & \multicolumn{2}{c}{ Alta Produtividade } & \multicolumn{2}{c}{ Média Produtividade } \\
\cline { 2 - 7 } & Composição & Estrutural & Composição & Estrutural & Composição & Estrutural \\
\hline \multirow{2}{*}{ Q90 } & $-0,046^{* * *}$ & $0,136^{* * *}$ & $0,0729^{* * *}$ & $-0,088^{* * *}$ & $0,0198^{* * *}$ & $-0,053^{* * *}$ \\
& $(0,00176)$ & $(0,00996)$ & $(0,00319)$ & $(0,00862)$ & $(0,00277)$ & $(0,0129)$ \\
\hline \multirow{2}{*}{ Q70 } & $-0,029^{* * *}$ & $0,0219^{* * *}$ & $0,0342^{* * *}$ & $-0,00368$ & $0,0216^{* * *}$ & $-0,021^{* * *}$ \\
& $(0,000856)$ & $(0,00327)$ & $(0,00105)$ & $(0,00299)$ & $(0,000886)$ & $(0,00465)$ \\
\hline \multirow{2}{*}{ Q50 } & $-0,025^{* * *}$ & $0,0077^{* * *}$ & $0,0268^{* * *}$ & $0,0157^{* * *}$ & $0,0175^{* * *}$ & $0,0108^{* * *}$ \\
& $(0,0007000)$ & $(0,00260)$ & $(0,000824)$ & $(0,00238)$ & $(0,000701)$ & $(0,00371)$ \\
\hline \multirow{2}{*}{ Q30 } & $-0,023^{* * *}$ & $-0,008^{* * *}$ & $0,0175^{* * *}$ & $0,0363^{* * *}$ & $0,00940^{* * *}$ & $0,0431^{* * *}$ \\
& $(0,000707)$ & $(0,00255)$ & $(0,000716)$ & $(0,00237)$ & $(0,000627)$ & $(0,00372)$ \\
\hline \multirow{2}{*}{ Q10 } & $-0,016^{* * *}$ & $-0,00194$ & $0,0125^{* * *}$ & $0,0168^{* * *}$ & $-0,0041^{* * *}$ & $0,0493^{* * *}$ \\
& $(0,000872)$ & $(0,00448)$ & $(0,00130)$ & $(0,00394)$ & $(0,00120)$ & $(0,00599)$ \\
\hline
\end{tabular}

Nota: Baixa produtividade como base de comparação.

Fonte: Elaboração própria. 
Para quantis mais altos, o resultado muda quando se analisa o efeito de estar em um subsetor de alta e de média produtividade em comparação com um subsetor de baixa produtividade. Observa-se que mulheres em subsetores de alta produtividade têm retornos salariais maiores que homens nesses mesmos setores, o que contribui para reduzir o diferencial de salário no quantil mais alto (90), apesar disso, nesse quantil, de acordo com a parte explicada, os salários dos homens é maior por estarem alocados em subsetores com os maiores níveis de produtividade em proporção maior do que as mulheres. Pode-se dizer que, para o quantil mais alto, em comparação com subsetores de baixa produtividade, nos subsetores de alta produtividade, os salários das mulheres são maiores, apesar de ter poucas mulheres atuando nestes subsetores, como visto também na Tabela 5. Como evidenciado por Flabbi et al. (2019), aumentar a representatividade feminina contribuirá para reduzir o hiato de gênero no topo da distribuição por meio de uma maior participação em cargos de liderança. O mesmo ocorre para os subsetores de média e alta produtividade da indústria de transformação brasileira.

Em comparação com subsetores de baixa produtividade, o impacto na mediana indica que estar em um subsetor de alta ou de média produtividade aumenta ainda mais as diferenças salariais, tanto por ter menos mulheres atuando (efeito de composição), como pelos retornos salariais serem menores para elas (efeito estrutural).

Sugere-se que as diferenças salariais no topo da distribuição, para subsetores com média e alta produtividade, são devidos à baixa representatividade feminina, sendo os retornos salariais de estar nestes subsetores importantes para reduzir o hiato de gênero. Em uma análise sobre os diferenciais médios, Bonini e Pozzobon (2016) constataram um comportamento semelhante em que os efeitos estruturais são favoráveis às mulheres. Em uma análise para a área de Tecnologia da Informação da Região Sul brasileira, foi evidenciada baixa participação feminina, mas há indícios que as mulheres apresentam maiores vantagens salariais quando inseridas na área.

Os resultados apresentados na Tabela 6 revelam diferentes efeitos da produtividade para os grupos, sendo a produtividade capaz de reduzir o hiato de gênero em alguns casos (quantis inferiores) e incapaz em outros (quantis superiores). Além disso, a comparação entre níveis de produtividade apresentou diferentes comportamentos dos efeitos de composição e estrutural. Isso indica a necessidade de uma análise mais detalhada em relação aos níveis de produtividade e o efeito dessa estratificação para os gêneros. Os resultados da decomposição para cada nível de produtividade, detalhando os diferenciais de rendimentos, são apresentados na Tabela 7, especificados de acordo com a equação (4). 


\section{Tabela 7 - Decomposição do hiato de gênero por segmentos de produtividade e quantis}

\begin{tabular}{|c|c|c|c|c|c|}
\hline \multirow[t]{2}{*}{ Quantis } & \multicolumn{2}{|c|}{ Coeficientes } & \multicolumn{3}{|c|}{ Diferenciais } \\
\hline & Homens & Mulheres & Composição & Estrutural & Totais \\
\hline \multicolumn{6}{|c|}{ Alta Produtividade } \\
\hline \multirow{2}{*}{10} & $0,662^{* * *}$ & $0,582^{* * *}$ & $0,152^{* * *}$ & $-0,0713^{* * *}$ & $0,0805^{* * *}$ \\
\hline & $(0,00467)$ & $(0,00752)$ & $(0,00861)$ & $(0,00451)$ & $(0,00885)$ \\
\hline \multirow{2}{*}{50} & $1,381^{* * *}$ & $1,129^{* * *}$ & $-0,0833^{* * *}$ & $0,336^{\star * *}$ & $0,252^{* * *}$ \\
\hline & $(0,00412)$ & $(0,00661)$ & $(0,00476)$ & $(0,00693)$ & $(0,00779)$ \\
\hline \multirow{2}{*}{90} & $2,599^{* * *}$ & $2,457^{\star * *}$ & $-0,186^{* * *}$ & $0,328^{* * *}$ & $0,142^{* * *}$ \\
\hline & $(0,0120)$ & $(0,0246)$ & $(0,0155)$ & $(0,0259)$ & $(0,0273)$ \\
\hline \multicolumn{6}{|c|}{ Média Produtividade } \\
\hline \multirow{2}{*}{10} & $0,416^{* * *}$ & $0,269^{* * *}$ & $-0,0893^{* * *}$ & $0,236^{* * *}$ & $0,147^{* * *}$ \\
\hline & $(0,00356)$ & $(0,00756)$ & $(0,00453)$ & $(0,00782)$ & $(0,00835)$ \\
\hline \multirow{2}{*}{50} & $1,075^{\star * *}$ & $0,888^{\star * *}$ & $-0,0637^{\star * *}$ & $0,250^{\star * *}$ & $0,186^{\star * *}$ \\
\hline & $(0,00267)$ & $(0,00377)$ & $(0,00255)$ & $(0,00407)$ & $(0,00462)$ \\
\hline \multirow{2}{*}{90} & $2,053^{\star * *}$ & $1,825^{* * *}$ & $-0,230^{* * *}$ & $0,457^{* * *}$ & $0,227^{\star * *}$ \\
\hline & $(0,00657)$ & $(0,0147)$ & $(0,00934)$ & $(0,0146)$ & $(0,0161)$ \\
\hline \multicolumn{6}{|c|}{ Baixa Produtividade } \\
\hline \multirow{2}{*}{10} & $0,297^{* * *}$ & $0,272^{* * *}$ & $-0,0889^{* * *}$ & $0,114^{\star * *}$ & $0,0250^{* * *}$ \\
\hline & $(0,00561)$ & $(0,00511)$ & $(0,00365)$ & $(0,00764)$ & $(0,00759)$ \\
\hline \multirow{2}{*}{50} & $0,830^{* * *}$ & $0,745^{\star * *}$ & $-0,0675^{\star * *}$ & $0,153^{\star * *}$ & $0,0851^{* * *}$ \\
\hline & $(0,00397)$ & $(0,00255)$ & $(0,00215)$ & $(0,00446)$ & $(0,00471)$ \\
\hline \multirow{2}{*}{90} & $1,605^{* * *}$ & $1,259^{* * *}$ & $-0,0734^{* * *}$ & $0,419^{* * *}$ & $0,346^{* * *}$ \\
\hline & $(0,01000)$ & $(0,00698)$ & $(0,00564)$ & $(0,0116)$ & $(0,0122)$ \\
\hline
\end{tabular}

Nota: Erros padrão em parênteses.

Fonte: Elaboração própria.

Os resultados da decomposição para cada nível de produtividade trazem informações importantes para todos os segmentos de produtividade (Tabela 7). Em todos os estratos de produtividade, verifica-se um diferencial de rendimentos desfavorável às mulheres, visto que os efeitos totais apresentaram sinal positivo e significativo em todos os quantis analisados. No entanto, pode-se ver que, independentemente do estrato, esse diferencial deve-se a questões estruturais, com exceção do quantil mais baixo em subsetores de alta produtividade. Conforme a Equação 3, os efeitos de composição são dados pelas variáveis independentes utilizadas para a estimação dos rendimentos, entre elas, destacam-se as variáveis de escolaridade e experiência, enquanto os termos não explicados (efeitos estruturais) podem ser as características não observadas ou a diferença de tratamento para homens e mulheres. Nesse sentido, mesmo apresentando características produtivas favoráveis, as mulheres podem estar sofrendo algum tipo de discriminação, 
visto que os retornos salariais não condizem com suas produtividades. Nota-se também que o diferencial dado pelo efeito estrutural aumenta com os quantis em subsetores de baixa e média produtividade. Com isso, pode-se concluir que o fenômeno "teto de vidro" ocorre principalmente para tais estratos de produtividade.

Para mulheres que se encontram no topo das distribuições de rendimentos, quanto maior o nível de produtividade da indústria em que estão empregadas, menores serão suas desvantagens salariais. Para os indivíduos que se encontram no último quantil de rendimentos, o maior diferencial encontra-se no segmento de baixa produtividade, seguido do estrato de média produtividade e o menor diferencial nas indústrias de maior nível de produtividade. Esses resultados sugerem que as mulheres com alto nível de qualificação seriam atraídas para os setores mais produtivos, entretanto, como já observado, esses mesmos setores apresentam uma baixa representatividade feminina nos cargos de chefia, aqueles que comumente oferecem maiores rendimentos. Para os demais quantis, o hiato de gênero mostra-se menor nos estratos industriais de baixa produtividade. Excetuando os cargos de chefia (diretorias e gerências), as mulheres têm maior representatividade em todos os outros tipos de ocupações em relação aos demais estratos de produtividade. $\mathrm{O}$ que também pode contribuir para os menores gaps nos setores de menor produtividade são os baixos rendimentos, recebidos por ambos os gêneros.

Nesse sentido, na Tabela 8, destaca-se a importância da escolaridade nos diferenciais de salários por nível de produtividade. Verifica-se que para todos os quantis e níveis de produtividade os coeficientes explicados têm valores negativos, o que corrobora com a vantagem feminina em escolaridade em relação aos homens, evidenciado pela literatura (MEIRELES, 2014; BLAU; KAHN, 2017; PEREIRA; OLIVEIRA, 2017).

O efeito de composição mostra a diferença dos valores da variável explicada apresentados por cada grupo, mostrando-se favorável à redução do hiato de gênero em todos os quantis. Já o efeito estrutural, que apresenta a diferença dos retornos da variável explicativa entre os grupos analisados e que estão ligados a fatores não observáveis, mostra a diferença dos retornos das características dos indivíduos, ou seja, quando são diferentes de zero, significam que os grupos têm diferentes retornos salariais para as mesmas características produtivas. Quando as diferenças não explicadas apresentam sinal positivo, essas mostram retornos da variável explicativa maiores para os homens e quando o sinal é negativo e retornos maiores para as mulheres.

A análise dos efeitos não explicados da escolaridade revela importantes informações. A presença feminina nos segmentos de baixa produtividade implica menores retornos da escolaridade em seus rendimentos para todos os quantis, e essa diferença mostra-se maior para os níveis de rendimentos mais altos. Isso poderia ser esperado devido à baixa representatividade feminina em cargos de diretoria para esse estrato, como visto na Tabela 2. As mulheres que se encontram no topo da distribuição de rendimentos 
estão em uma situação mais vantajosa em termos de retorno da escolaridade quando estão nos setores de produtividade média. Apesar da diferença dos coeficientes de rendimentos serem menores para os setores de alta produtividade, no topo da distribuição, a diferença entre os retornos da escolaridade apresenta, em favor das mulheres, seu maior nível para os segmentos de produtividade média, o que também pode estar associado com a maior representatividade em cargos de diretoria nesses setores.

$\mathrm{Na}$ base da distribuição de rendimentos, as mulheres apresentam vantagem nos retornos da escolaridade apenas nos segmentos de média produtividade, entretanto, nesses mesmos segmentos, elas apresentam maior desvantagem a respeito dos retornos salariais da escolaridade.

Tabela 8 - Efeitos da escolaridade na decomposição do hiato de gênero por quantis

\begin{tabular}{ccccccc}
\hline & \multicolumn{2}{c}{ Alta Produtividade } & \multicolumn{2}{c}{ Média Produtividade } & \multicolumn{2}{c}{ Baixa Produtividade } \\
\cline { 2 - 7 } & Composição & Estrutural & Composição & Estrutural & Composição & Estrutural \\
\hline \multirow{2}{*}{ Q90 } & $-0,161^{* * *}$ & $-0,126^{* * *}$ & $-0,175^{* * *}$ & $-0,504^{* * *}$ & $-0,057^{* * *}$ & $0,251^{* * *}$ \\
& $(0,0107)$ & $(0,103)$ & $(0,00676)$ & $(0,0479)$ & $(0,00315)$ & $(0,0341)$ \\
\hline \multirow{2}{*}{ Q70 } & $-0,136^{* * *}$ & $-0,365^{* * *}$ & $-0,078^{* * *}$ & $-0,013^{* * *}$ & $-0,022^{* * *}$ & $0,221^{* * *}$ \\
& $(0,00644)$ & $(0,0426)$ & $(0,00267)$ & $(0,0169)$ & $(0,00127)$ & $(0,0158)$ \\
\hline \multirow{2}{*}{ Q50 } & $-0,080^{* * *}$ & 0,001 & $-0,055^{* * *}$ & $0,114^{* * *}$ & $-0,015^{* * *}$ & $0,166^{* * *}$ \\
& $(0,00385)$ & $(0,0274)$ & $(0,00193)$ & $(0,0133)$ & $(0,000935)$ & $(0,0131)$ \\
\hline \multirow{2}{*}{ Q30 } & $-0,063^{* * *}$ & $0,084^{* * *}$ & $-0,046^{* * *}$ & $0,143^{* * *}$ & $-0,014^{* * *}$ & $0,100^{* * *}$ \\
& $(0,00326)$ & $(0,0264)$ & $(0,00175)$ & $(0,0133)$ & $(0,000997)$ & $(0,0136)$ \\
\hline \multirow{2}{*}{ Q10 } & $-0,053^{* * *}$ & $0,165^{* * *}$ & $-0,073^{* * *}$ & $-0,112^{* * *}$ & $-0,021^{* * *}$ & $0,0503^{* * *}$ \\
& $(0,00343)$ & $(0,0341)$ & $(0,00321)$ & $(0,0256)$ & $(0,00166)$ & $(0,0224)$ \\
\hline
\end{tabular}

Nota: Erros padrão entre parênteses.

Fonte: Elaboração própria.

Em uma análise sem especificar o nível de produtividade e para todo o mercado de trabalho brasileiro, Meireles (2014) também destaca a importância do nível de escolaridade para a redução do diferencial de salário via efeito composição, mas também devido ao efeito estrutural. Pelo exposto na Tabela 8 , apesar do efeito de composição ser favorável à redução das diferenças de rendimento entre homens e mulheres, somente em duas situações a escolaridade se traduz em retornos positivos às mulheres (quantil 70, em subsetores de alta produtividade e quantil 10 em subsetores de média produtividade). Com isso, pode-se ver como uma decomposição salarial específica para um setor com baixa representatividade feminina, que leva em consideração os níveis de produtividade, pode reforçar a percepção acerca da existência de barreiras que impedem as mulheres de alcançarem níveis salariais semelhantes aos dos homens, mesmo quando estas têm iguais características produtivas. 


\section{CONSIDERAÇÕES FINAIS}

Com o presente estudo, buscou-se verificar como o hiato de gênero se relaciona com a produtividade nos diferentes tipos de indústrias encontradas na indústria de transformação brasileira. Como proxy para produtividade, foi construída uma variável com base no total das receitas líquidas de vendas de cada subsetor da indústria de transformação e o pessoal empregado nesses subsetores. Após a construção da proxy e estratificação dos subsetores por produtividade, foi realizada uma decomposição com abordagem quantílica para verificar a existência do hiato de gênero e como ele se comporta ao longo da distribuição salarial e por níveis de produtividade. Além disso, a presente pesquisa contribui com evidências de como o hiato de gênero se manifesta na indústria de transformação brasileira, setor com baixa representação feminina. Mostra-se também a necessidade de um esforço maior por parte das indústrias para aumentar tal representatividade, principalmente no topo da distribuição de rendimentos.

Os resultados obtidos mostram que, para cada quantil de rendimentos, a relação da produtividade com o hiato salarial mostra-se diferente. Para trabalhadores de altos cargos que se encontram entre aqueles que têm maiores rendimentos, a produtividade do setor tem papel importante para a redução das desigualdades entre homens e mulheres. É no estrato de baixa de produtividade que há a maior diferença de rendimentos entre os gêneros nos níveis mais elevados de salários e ausência de mulheres em cargos de diretoria, o que demonstra grande desvantagem para o gênero feminino nesse nível de produtividade em relação aos níveis de média e alta produtividade. Já para aqueles trabalhadores que se encontram na base da distribuição de rendimentos, o gap é menor nos setores menos produtivos, em contrapartida, os salários tanto para homens quanto para mulheres são menores nesses setores.

Ainda em relação às tabelas, há indícios que corroboram para a existência de um "teto de vidro" nos subsetores da indústria de transformação do Brasil. Verifica-se que as representatividades femininas são consideravelmente menores nos cargos de chefia (diretoria e gerência) para todos os estratos analisados. Ainda assim, mesmo quando as mulheres conseguem alcançar altos cargos, os hiatos verificados para o topo da distribuição de rendimentos mostram-se elevados. Esses fatores podem estar ligados à predominância de homens nos melhores cargos e nos setores de melhores rendimentos, o que poderia acarretar ambientes mais favoráveis à valorização dos homens em detrimento das mulheres.

A relação entre produtividade e o hiato de gênero mostrou-se diferente da esperada em alguns casos. A exemplo, pode-se verificar que é vantajoso para as mulheres estarem alocadas em segmentos menos produtivos, principalmente quando elas ocupam cargos que oferecem menores rendimentos e exigem menores níveis de qualificação. 
A estratégia empírica utilizada apresenta algumas limitações, principalmente em relação à construção da variável de produtividade. A limitação dos dados disponíveis impossibilitou a estimação da produtividade, o que seria uma medida mais adequada do que a proxy aqui utilizada. Além disso, sugere-se que pesquisas futuras analisem a relação do diferencial de gênero com a competitividade das indústrias, o que pode trazer uma análise mais consistente com a teoria do capital humano.

\section{REFERÊNCIAS}

ALVES, J. E. D.; CAVENAGHI, S. M. Indicadores de desigualdade de gênero no Brasil. Mediações, v. 18, n. 1, p. 83-105, 2013.

ANGRIST, J. D.; PISCHKE, J. S. Mostly harmless econometrics: An empiricist's companion. Princeton: Princeton University Press, 2008.

BARTALOTTI, O. A. C. Discriminação salarial por cor e gênero revisitada: Uma abordagem de decomposição contrafactual utilizando regressões quantílicas. 2007. Dissertação (Mestrado em Economia) - Fundação Getúlio Vargas, São Paulo, 2007.

BARTH, E. et al. The effects of scientists and engineers on productivity and earnings at the establishment where they work. Cambridge: National Bureau of Economic Research, 2017.

BECKER, G. S. Investment in human capital: A theoretical analysis. Journal of Political Economy, v. 70, n. 5, p. 9-49, 1962.

BEEDE, D. N. et al. Women in STEM: A gender to innovation. Economics and Statistics Administration Issue Brief, n. 4-11, p. 1-11, 2011.

BLAU, F. D.; KAHN, L. M. The gender wage gap: Extent, trends, and explanations. Journal of Economic Literature, v. 55, n. 3, p. 789-865, 2017.

BLINDER, A. S. Wage discrimination: reduced form and structural estimates. Journal of Human Resources, v. 8, n. 4, p. 436-455, 1973.

BOBBITT-ZEHER, D. The gender income gap and the role of education. Sociology of Education, v. 80, n. 1, p. 1-22, 2007.

BONINI, P.; POZZOBON, F. Discriminação salarial feminina e o prêmio salarial de TI na indústria de tecnologia da Região Sul. Análise Econômica, v. 34, n. 66, p. 193-223, 2016.

BRASIL. Relação Anual de Informações Sociais. Vários Anos. [Online] Ministério do Trabalho e Emprego, 2018. Disponível em: https://bit.ly/3wAgTF8. Acesso em: 1 ago. 2018.

CARD, D.; CARDOSO, A. R.; KLINE, P. Bargaining, sorting, and the gender wage gap: Quantifying the impact of firms on the relative pay of women. The Quarterly Journal of Economics, v. 131, n. 2, p. 633-686, 2015.

COELHO, D.; FERNANDES, M.; FOGUEL, M. N. Diferenciais de gênero na promoção em grandes empresas da indústria brasileira. Mercado de Trabalho, v. 42, p. 21-25, 2010.

FLABBI, L. et al. Do female executives make a difference? The impact of female leadership on gender gaps and firm performance. The Economic Journal, v. 129, n. 622, p. 2390-2423, 2019. 
FIRPO, S.; FORTIN, N. M.; LEMIEUX, T. Unconditional quantile regressions. Econometrica, v. 77, n. 3, p. 953-973, 2009.

FIRPO, S. P.; FORTIN, N. M.; LEMIEUX, T. Decomposing wage distributions using recentered influence function regressions. Econometrics, v. 6, n. 2, p. 28, 2018.

GIUBERTI, A. C.; MENEZES-FILHO, N. Discriminação de rendimentos por gênero: Uma comparação entre o Brasil e os Estados Unidos. Economia Aplicada, v. 9, n. 3, p. 369-384, 2005.

IBGE - INSTITUTO BRASILEIRO DE GEOGRAFIA E ESTATÍSTICA. Classificação Nacional de Atividades Econômicas. Rio de Janeiro: IBGE, 2018a. Disponível em: https://bit.ly/3fwXm2Y. Acesso em: 31 ago. 2018.

IBGE - INSTITUTO BRASILEIRO DE GEOGRAFIA E ESTATÍSTICA. Pesquisa Industrial Anual. Vários Anos. Rio de Janeiro: IBGE, 2018b. Disponível em: https://bit.ly/3ckagiP. Acesso em: 31 ago. 2018.

IBGE - INSTITUTO BRASILEIRO DE GEOGRAFIA E ESTATÍSTICA. Pesquisa Nacional por Amostra de Domicílios: Microdados. Rio de Janeiro: IBGE, 2018c. Disponível em: https://bit. ly/3yNIdSo. Acesso em: 31 ago. 2018.

LAVINAS, L. Empregabilidade no Brasil: Inflexões de gênero e diferenciais femininos. Rio de Janeiro: IPEA, 2001.

MEIRELES, D. C. Diferenciais de rendimentos por gênero: Uma análise dos efeitos composição e estrutura salarial no Brasil (1976, 1987, 1996 e 2009). 2014. Dissertação (Mestrado em Economia Regional) - Universidade Federal do Rio Grande do Norte, Natal, 2014.

PEREIRA, R. M.; OLIVEIRA, C. A. Discriminação por gênero no mercado de trabalho local: um estudo para os municípios do Rio Grande do Sul. Análise Econômica, v. 35, n. 68, p. 87-116, 2017.

POWELL, G.; BUTTERFIELD, A. The glass ceiling: what have we learned 20 years on? Journal of Organizational Effectiveness: People and Performance, v. 2, n. 4, p. 306-326, 


\section{APÊNDICE}

Tabela A1 Coeficientes estimados das variáveis explicativas para o estrato de alta produtividade

\begin{tabular}{|c|c|c|c|c|c|c|c|c|c|c|}
\hline & \multicolumn{2}{|c|}{ Q10 } & \multicolumn{2}{|c|}{ Q30 } & \multicolumn{2}{|c|}{ Q50 } & \multicolumn{2}{|c|}{ Q70 } & \multicolumn{2}{|c|}{ Q90 } \\
\hline Variáveis & Explicadas & $\begin{array}{c}\text { Não } \\
\text { explicadas }\end{array}$ & Explicadas & $\begin{array}{c}\text { Não } \\
\text { explicadas }\end{array}$ & Explicadas & $\begin{array}{c}\text { Não } \\
\text { explicadas }\end{array}$ & Explicadas & $\begin{array}{c}\text { Não } \\
\text { explicadas }\end{array}$ & Explicadas & $\begin{array}{c}\text { Não } \\
\text { explicadas }\end{array}$ \\
\hline \multirow{2}{*}{ Esc } & $-0.0538^{* * *}$ & $0.165^{\star * *}$ & $-0.0630^{* * *}$ & $0.0849^{* * *}$ & $-0.0805^{\star * *}$ & 0.00153 & $-0.136^{* * *}$ & $-0.365^{* * *}$ & $-0.161^{* * *}$ & -0.126 \\
\hline & $(0.00343)$ & $(0.0341)$ & $(0.00326)$ & $(0.0264)$ & $(0.00385)$ & $(0.0274)$ & $(0.00644)$ & $(0.0426)$ & $(0.0107)$ & $(0.103)$ \\
\hline Exp & $(0.00529)$ & $(0.0412)$ & $(0.00426)$ & $(0.0319)$ & $(0.00447)$ & $(0.0331)$ & $(0.00730)$ & $(0.0511)$ & $(0.0190)$ & $(0.123)$ \\
\hline \multirow{2}{*}{ Exp2 } & 0.00412 & $-0.122^{\star * *}$ & -0.00588 & $-0.129^{\star * *}$ & -0.00354 & $-0.176^{\star * *}$ & $8.68 \mathrm{e}-05$ & $-0.232^{\star * *}$ & $-0.0870^{\star * *}$ & 0.116 \\
\hline & $(0.00499)$ & $(0.0251)$ & $(0.00388)$ & $(0.0195)$ & $(0.00399)$ & $(0.0202)$ & $(0.00647)$ & $(0.0314)$ & $(0.0165)$ & $(0.0757)$ \\
\hline Sind & $-0.0105^{\star * *}$ & $0.0220^{\star *}$ & $-0.00981^{* * *}$ & $0.0120^{*}$ & $-0.00862^{\star * *}$ & 0.00638 & $-0.0106^{\star * *}$ & -0.00557 & $-0.0138^{\star * *}$ & -0.0287 \\
\hline \multirow{2}{*}{ Rurb } & $0.00697^{\star * *}$ & $0.0294^{\star * *}$ & $0.00612^{\star \star * *}$ & $0.0263^{* * *}$ & $0.00552^{\star * *}$ & $0.0331^{* * *}$ & $0.00797^{\star * *}$ & $0.0173^{* *}$ & 0.00164 & 0.0197 \\
\hline & $(0.00124)$ & $(0.00607)$ & $(0.000980)$ & $(0.00471)$ & $(0.000987)$ & $(0.00488)$ & $(0.00158)$ & $(0.00757)$ & $(0.00361)$ & $(0.0183)$ \\
\hline \multirow{2}{*}{ RPP } & $-0.00128^{* *}$ & 0.0506 & $-0.000622^{* *}$ & $0.0534^{*}$ & $-0.000601^{\star *}$ & 0.0185 & -0.000580 & -0.0292 & -0.000607 & -0.0925 \\
\hline & $(0.000506)$ & $(0.0382)$ & $(0.000281)$ & $(0.0296)$ & $(0.000279)$ & $(0.0307)$ & $(0.000357)$ & $(0.0476)$ & $(0.000749)$ & $(0.115)$ \\
\hline \multirow{2}{*}{ Dir } & $4.20 \mathrm{e}-06$ & -0.000294 & $2.39 \mathrm{e}-05$ & -0.000157 & $3.33 e-05$ & 0.000405 & 0.000121 & 0.000708 & 0.000528 & $0.00226^{\star}$ \\
\hline & $(2.58 \mathrm{e}-05)$ & $(0.000437)$ & $(9.75 \mathrm{e}-05)$ & $(0.000338)$ & $(0.000135)$ & $(0.000353)$ & $(0.000489)$ & $(0.000547)$ & $(0.00213)$ & $(0.00133)$ \\
\hline \multirow{2}{*}{ Ger } & $-0.000593^{*}$ & $-0.00408^{* *}$ & $-0.00132^{\star *}$ & -0.00149 & $-0.00235^{\star \star *}$ & 0.00214 & $-0.00577^{* * *}$ & -0.000965 & $-0.0128^{\star * *}$ & $0.0108^{\star *}$ \\
\hline & $(0.000309)$ & $(0.00175)$ & $(0.000524)$ & $(0.00136)$ & $(0.000901)$ & $(0.00141)$ & $(0.00219)$ & $(0.00217)$ & $(0.00486)$ & $(0.00522)$ \\
\hline \multirow{2}{*}{ Cienc } & $-0.00210^{*}$ & $-0.00403^{* *}$ & $-0.00889^{* * *}$ & -0.00118 & $-0.0180^{* * *}$ & $0.00299^{* *}$ & $-0.0488^{\star * *}$ & 0.00243 & $-0.103^{\star * *}$ & $0.0442^{* * *}$ \\
\hline & $(0.00125)$ & $(0.00165)$ & $(0.00113)$ & $(0.00128)$ & $(0.00155)$ & $(0.00133)$ & $(0.00359)$ & $(0.00200)$ & $(0.00781)$ & $(0.00489)$ \\
\hline Tec & $(0.000490)$ & $(0.00314)$ & $(0.000700)$ & $(0.00243)$ & $(0.000985)$ & $(0.00252)$ & $(0.00183)$ & $(0.00388)$ & $(0.00176)$ & $(0.00935)$ \\
\hline \multicolumn{11}{|c|}{ Coeficientes gerais } \\
\hline \multirow{2}{*}{ Homens } & \multicolumn{2}{|c|}{$0.662^{* * *}$} & \multicolumn{2}{|c|}{$1.066^{* * *}$} & \multicolumn{2}{|c|}{$1.381^{\star * *}$} & \multicolumn{2}{|c|}{$1.764^{\star * *}$} & \multicolumn{2}{|c|}{$2.599^{* * *}$} \\
\hline & \multicolumn{2}{|c|}{$(0.00467)$} & \multicolumn{2}{|c|}{$(0.00379)$} & \multicolumn{2}{|c|}{$(0.00412)$} & \multicolumn{2}{|c|}{$(0.00561)$} & $(0.0$ & 120) \\
\hline & 0.58 & & 0.88 & $9^{* * *}$ & 1.12 & $9^{* * *}$ & 1.49 & $9^{* * *}$ & 2.45 & $7^{* * *}$ \\
\hline 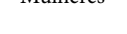 & $(0.00$ & 752) & $(0.00$ & 609) & $(0.00$ & 661) & $(0.0$ & 113) & $(0.0$ & 246) \\
\hline Diferenças & 0.080 & $5^{* * *}$ & 0.17 & $7^{* * *}$ & 0.25 & $2^{* * *}$ & 0.26 & $5^{* * *}$ & 0.14 & $2^{* * *}$ \\
\hline Totais & $(0.00$ & 885) & $(0.00$ & 717) & $(0.00$ & 779) & $(0.0$ & 126) & $(0.0$ & 273) \\
\hline & -0.07 & $13^{* * *}$ & -0.07 & $19^{* * *}$ & -0.08 & $33^{* * *}$ & -0.14 & $3^{* * *}$ & -0.18 & $6^{* * *}$ \\
\hline Lispillatias & $(0.00$ & 451) & $(0.00$ & 403) & $(0.00$ & 476) & $(0.00$ & 858) & $(0.0$ & 155) \\
\hline Não & 0.15 & & 0.24 & $9^{* * *}$ & 0.33 & $6^{* * *}$ & 0.40 & $8^{* * *}$ & 0.32 & $8^{* * *}$ \\
\hline explicadas & $(0.00$ & 861) & $(0.00$ & 669) & $(0.00$ & 693) & $(0.0$ & 108) & $(0.0$ & 259) \\
\hline & -0.24 & $9^{* * *}$ & -0.18 & $9^{* * *}$ & -0.0 & 426 & 1.76 & $4^{* * *}$ & 0.78 & $6^{* * *}$ \\
\hline Comstante & $(0.0$ & 34) & $(0.0$ & 492) & $(0.0$ & 509) & $(0.00$ & 561) & $(0.1$ & 92) \\
\hline Observações & 47 & & 47 & 788 & 47 & 788 & 47 & 788 & 47 & 788 \\
\hline
\end{tabular}




\section{Tabela A2 Coeficientes estimados das variáveis explicativas para o estrato de média produtividade}

\begin{tabular}{|c|c|c|c|c|c|c|c|c|c|c|}
\hline & \multicolumn{2}{|c|}{ Q10 } & \multicolumn{2}{|c|}{ Q30 } & \multicolumn{2}{|c|}{ Q50 } & \multicolumn{2}{|c|}{ Q70 } & \multicolumn{2}{|c|}{ Q90 } \\
\hline Variáveis & Explicadas & $\begin{array}{c}\text { Não } \\
\text { explicadas }\end{array}$ & Explicadas & $\begin{array}{c}\text { Não } \\
\text { explicadas }\end{array}$ & Explicadas & $\begin{array}{c}\text { Não } \\
\text { explicadas }\end{array}$ & Explicadas & $\begin{array}{c}\text { Não } \\
\text { explicadas }\end{array}$ & Explicadas & $\begin{array}{c}\text { Não } \\
\text { explicadas }\end{array}$ \\
\hline \multirow{2}{*}{ Esc } & $-0.0735^{\star * *}$ & $-0.112^{\star \star *}$ & $-0.0468^{\star * *}$ & $0.143^{\star \star *}$ & $-0.0551^{\star * *}$ & $0.114^{* * *}$ & $-0.0782^{* * *}$ & -0.0137 & $-0.175^{\star * *}$ & $-0.504^{* * *}$ \\
\hline & $(0.00321)$ & $(0.0256)$ & $(0.00175)$ & $(0.0133)$ & $(0.00193)$ & $(0.0133)$ & $(0.00267)$ & $(0.0169)$ & $(0.00676)$ & $(0.0479)$ \\
\hline \multirow{2}{*}{ Exp } & $0.0258^{* * *}$ & $0.0868^{\star *}$ & $0.0172^{\star * *}$ & $0.302^{* * *}$ & $0.0179^{\star * *}$ & $0.410^{* * *}$ & $0.0273^{* * *}$ & $0.408^{\star * *}$ & $0.0896^{\star * *}$ & 0.0208 \\
\hline & $(0.00331)$ & $(0.0379)$ & $(0.00170)$ & $(0.0201)$ & $(0.00173)$ & $(0.0199)$ & $(0.00240)$ & $(0.0253)$ & $(0.00754)$ & $(0.0710)$ \\
\hline \multirow{2}{*}{$\operatorname{Exp} 2$} & $-0.0157^{\star * *}$ & 0.0118 & $-0.00743^{* * *}$ & $-0.0960^{* * *}$ & $-0.00527^{\star * *}$ & $-0.156^{* * *}$ & $-0.00811^{\star * *}$ & $-0.171^{\star * *}$ & $-0.0388^{* * *}$ & -0.0367 \\
\hline & $(0.00310)$ & $(0.0226)$ & $(0.00146)$ & $(0.0118)$ & $(0.00143)$ & $(0.0117)$ & $(0.00190)$ & $(0.0150)$ & $(0.00602)$ & $(0.0423)$ \\
\hline \multirow{2}{*}{ Sind } & $-0.0212^{\star \star \star}$ & $-0.0482^{* * *}$ & $-0.0116^{\star \star *}$ & $0.0172^{\star * *}$ & $-0.0106^{\star * *}$ & $0.0148^{* * *}$ & $-0.00952^{\star \star *}$ & $0.0132^{\star * *}$ & $-0.0123^{\star \star *}$ & -0.00930 \\
\hline & $(0.00149)$ & $(0.00756)$ & $(0.000763)$ & $(0.00399)$ & $(0.000725)$ & $(0.00396)$ & $(0.000790)$ & $(0.00503)$ & $(0.00197)$ & $(0.0142)$ \\
\hline \multirow{2}{*}{ Rurb } & $0.00512^{\star * *}$ & -0.00390 & $0.00307^{\star * *}$ & $0.0134^{* * *}$ & $0.00257^{* * *}$ & $0.0157^{\star * *}$ & $0.00235^{\star * *}$ & $0.0169^{\star * *}$ & $0.00271^{* * *}$ & -0.00602 \\
\hline & $(0.000767)$ & $(0.00434)$ & $(0.000434)$ & $(0.00228)$ & $(0.000379)$ & $(0.00226)$ & $(0.000391)$ & $(0.00288)$ & $(0.000841)$ & $(0.00812)$ \\
\hline \multirow{2}{*}{ RPP } & $-0.00375^{\star * *}$ & $-0.357^{\star * *}$ & $-0.000721^{* * *}$ & 0.0233 & $-0.000473^{* * *}$ & 0.0108 & $-0.000299^{\star *}$ & 0.0286 & 0.000241 & 0.0553 \\
\hline & $(0.00118)$ & $(0.0273)$ & $(0.000238)$ & $(0.0143)$ & $(0.000167)$ & $(0.0142)$ & $(0.000140)$ & $(0.0181)$ & $(0.000325)$ & $(0.0511)$ \\
\hline \multirow{2}{*}{ Dir } & $-2.88 \mathrm{e}-06$ & -0.000186 & $5.74 \mathrm{e}-05$ & $-0.000399^{* *}$ & $9.88 \mathrm{e}-05$ & -0.000249 & 0.000221 & -0.000198 & 0.00101 & -0.000110 \\
\hline & $(4.53 e-05)$ & $(0.000368)$ & $(6.91 \mathrm{e}-05)$ & $(0.000194)$ & $(0.000115)$ & $(0.000192)$ & $(0.000255)$ & $(0.000244)$ & $(0.00116)$ & $(0.000689)$ \\
\hline \multirow{2}{*}{ Ger } & $-5.07 e-05$ & 0.000185 & $-0.000554^{* *}$ & -0.000146 & $-0.00104^{\star *}$ & 0.000385 & $-0.00231^{* *}$ & -0.00126 & $-0.00959^{* *}$ & $-0.0313^{\star * *}$ \\
\hline & $(0.000125)$ & $(0.00143)$ & $(0.000241)$ & $(0.000760)$ & $(0.000444)$ & $(0.000754)$ & $(0.000980)$ & $(0.000956)$ & $(0.00405)$ & $(0.00274)$ \\
\hline \multirow{2}{*}{ Cienc } & $0.00587^{\star \star * *}$ & $0.00187^{\star}$ & $-0.00227^{\star * *}$ & 0.000483 & $-0.00757^{* * *}$ & $0.00196^{\star * *}$ & $-0.0192^{* * *}$ & $0.00296^{* * *}$ & $-0.0854^{* * *}$ & -0.00263 \\
\hline & $(0.00109)$ & $(0.000985)$ & $(0.000505)$ & $(0.000559)$ & $(0.000612)$ & $(0.000553)$ & $(0.00112)$ & $(0.000690)$ & $(0.00449)$ & $(0.00183)$ \\
\hline \multirow{2}{*}{ Tec } & -0.000239 & $-0.00398^{\star}$ & -0.000254 & 0.00162 & -0.000399 & 0.00137 & -0.000576 & $0.00361^{\star *}$ & -0.00116 & -0.00180 \\
\hline & $(0.000280)$ & $(0.00224)$ & $(0.000294)$ & $(0.00119)$ & $(0.000462)$ & $(0.00118)$ & $(0.000666)$ & $(0.00150)$ & $(0.00134)$ & $(0.00419)$ \\
\hline \multicolumn{11}{|c|}{ Coeficientes gerais } \\
\hline \multirow{2}{*}{ Homens } & \multicolumn{2}{|c|}{$0.416^{\star * *}$} & \multicolumn{2}{|c|}{$0.779^{\star * *}$} & \multicolumn{2}{|c|}{$1.075^{\star * *}$} & \multicolumn{2}{|c|}{$1.405^{* * *}$} & \multicolumn{2}{|c|}{$2.053^{\star * *}$} \\
\hline & \multicolumn{2}{|c|}{$(0.00356)$} & \multicolumn{2}{|c|}{$(0.00269)$} & \multicolumn{2}{|c|}{$(0.00267)$} & \multicolumn{2}{|c|}{$(0.00316)$} & $(0.0$ & 657) \\
\hline & 0.26 & & 0.65 & $* * *$ & 0.88 & $3 * * *$ & 1.16 & $3^{* * *}$ & 1.82 & $5^{* * *}$ \\
\hline Mrumeres & $(0.00$ & 756) & $(0.00$ & 373) & $(0.00$ & 377) & $(0.00$ & 496) & $(0.0$ & 147) \\
\hline Diferenças & 0.14 & $7 * * *$ & 0.12 & $* * *$ & 0.18 & $; * * *$ & 0.24 & $2^{* * *}$ & 0.22 & $7^{* * *}$ \\
\hline Totais & $(0.00$ & 835) & $(0.00$ & 160) & $(0.00$ & 462) & $(0.00$ & 588) & $(0.0$ & 161) \\
\hline & -0.08 & $3^{* * *}$ & -0.05 & $4^{* * *}$ & -0.06 & $7^{* * *}$ & -0.08 & $8^{* * *}$ & -0.2 & $0^{* * *}$ \\
\hline Laphicatias & $(0.00$ & 453) & $(0.00$ & 251) & $(0.00$ & 255) & $(0.00$ & 336) & $(0.0$ & 934) \\
\hline Não & 0.23 & & 0.17 & $* * *$ & 0.25 & *** & 0.33 & $2^{* * *}$ & 0.45 & $7^{\star * *}$ \\
\hline explicadas & $(0.00$ & 782) & $(0.00$ & 109) & $(0.00$ & 407) & $(0.00$ & 517) & $(0.0$ & 146) \\
\hline & 0.59 & & -0.35 & $4^{* * *}$ & -0.25 & $7^{* * *}$ & -0.0 & 574 & 0.86 & $9^{* * *}$ \\
\hline Comstante & $(0.0$ & & $(0.0$ & 83) & $(0.0$ & 82) & $(0.0$ & 58) & $(0.1)$ & 01) \\
\hline Observações & 95 & & 95 & & 95 & & 95 & & 95 , & 496 \\
\hline
\end{tabular}

Desvios-padrão em parênteses

$* * * p<0.01,{ }^{* *} p<0.05, * p<0.1$ 


\section{Tabela A3 Coeficientes estimados das variáveis explicativas para o estrato de baixa produtividade}

\begin{tabular}{|c|c|c|c|c|c|c|c|c|c|c|}
\hline \multirow[b]{2}{*}{ Variáveis } & \multicolumn{2}{|c|}{ Q10 } & \multicolumn{2}{|c|}{ Q30 } & \multicolumn{2}{|c|}{ Q50 } & \multicolumn{2}{|c|}{ Q70 } & \multicolumn{2}{|c|}{ Q90 } \\
\hline & Explicadas & $\begin{array}{c}\text { Não } \\
\text { explicadas }\end{array}$ & Explicadas & $\begin{array}{c}\text { Não } \\
\text { explicadas }\end{array}$ & Explicadas & $\begin{array}{c}\text { Não } \\
\text { explicadas }\end{array}$ & Explicadas & $\begin{array}{c}\text { Não } \\
\text { explicadas }\end{array}$ & Explicadas & $\begin{array}{c}\text { Não } \\
\text { explicadas }\end{array}$ \\
\hline \multirow{2}{*}{ Esc } & $-0.0210^{* * *}$ & $0.0503^{\star *}$ & $-0.0146^{\star * *}$ & $0.1000^{* * *}$ & $-0.0152^{\star * *}$ & $0.166^{\star * *}$ & $-0.0220^{\star * *}$ & $0.221^{\star * *}$ & $-0.0571^{\star * *}$ & $0.251^{\star * \star}$ \\
\hline & $(0.00166)$ & $(0.0224)$ & $(0.000997)$ & $(0.0136)$ & $(0.000935)$ & $(0.0131)$ & $(0.00127)$ & $(0.0158)$ & $(0.00315)$ & $(0.0341)$ \\
\hline \multirow{2}{*}{ Exp } & $-0.0216^{\star * *}$ & $0.0992^{\star * *}$ & $-0.0153^{\star * *}$ & $0.231^{\star * *}$ & $-0.0140^{* * *}$ & $0.363^{* * *}$ & $-0.0163^{\star \star \star}$ & $0.477^{\star * *}$ & $-0.0327^{\star * *}$ & $0.733^{\star * *}$ \\
\hline & $(0.00264)$ & $(0.0359)$ & $(0.00164)$ & $(0.0220)$ & $(0.00145)$ & $(0.0212)$ & $(0.00174)$ & $(0.0256)$ & $(0.00374)$ & $(0.0550)$ \\
\hline \multirow{2}{*}{ Exp2 } & $0.0138^{\star * *}$ & -0.00190 & $0.00789^{\star * *}$ & $-0.0718^{\star * *}$ & $0.00602^{\star * *}$ & $-0.126^{\star * *}$ & $0.00597^{* * *}$ & $-0.176^{\star \star \star}$ & $0.00964^{* * *}$ & $-0.305^{\star * *}$ \\
\hline & $(0.00208)$ & $(0.0198)$ & $(0.00117)$ & $(0.0121)$ & $(0.000948)$ & $(0.0117)$ & $(0.00109)$ & $(0.0141)$ & $(0.00234)$ & $(0.0303)$ \\
\hline \multirow{2}{*}{ Sind } & $-0.00997^{\star \star *}$ & -0.00386 & $-0.00849^{* * *}$ & $0.0109^{\star *}$ & $-0.00697^{\star * *}$ & $0.0288^{\star * *}$ & $-0.00766^{\star * *}$ & $0.0126^{\star *}$ & $-0.00887^{\star * *}$ & $0.0214^{*}$ \\
\hline & $(0.000989)$ & $(0.00756)$ & $(0.000754)$ & $(0.00462)$ & $(0.000622)$ & $(0.00446)$ & $(0.000701)$ & $(0.00537)$ & $(0.00105)$ & $(0.0116)$ \\
\hline \multirow{2}{*}{ Rurb } & 0.000170 & $-0.00740^{\star *}$ & $8.63 e-05$ & 0.000729 & $5.13 e-05$ & $0.00522^{* *}$ & $4.17 \mathrm{e}-05$ & $0.00480^{*}$ & $3.00 \mathrm{e}-05$ & -0.00485 \\
\hline & $(0.000718)$ & $(0.00366)$ & $(0.000364)$ & $(0.00224)$ & $(0.000217)$ & $(0.00216)$ & $(0.000176)$ & $(0.00260)$ & $(0.000128)$ & $(0.00561)$ \\
\hline \multirow{2}{*}{$\mathrm{RPP}$} & $-0.00158^{\star * *}$ & -0.0233 & $-0.000954^{* * *}$ & 0.00877 & $-0.000828^{* * *}$ & -0.00227 & $-0.000671^{\star \star}$ & -0.0152 & $-0.00122^{\star *}$ & -0.0290 \\
\hline & $(0.000484)$ & $(0.0265)$ & $(0.000270)$ & $(0.0160)$ & $(0.000230)$ & $(0.0152)$ & $(0.000272)$ & $(0.0184)$ & $(0.000619)$ & $(0.0399)$ \\
\hline \multirow{2}{*}{ Dir } & -0.000190 & 0.000137 & $3.87 e-05$ & 0.000105 & 0.000257 & $3.31 \mathrm{e}-05$ & $0.000683^{*}$ & $-5.61 e-06$ & $0.00406^{\star * *}$ & -0.000269 \\
\hline & $(0.000607)$ & $(0.000691)$ & $(0.000333)$ & $(0.000388)$ & $(0.000287)$ & $(0.000338)$ & $(0.000377)$ & $(0.000417)$ & $(0.00115)$ & $(0.000949)$ \\
\hline \multirow{2}{*}{ Ger } & $0.00167^{\star * *}$ & -0.00196 & $0.00238^{\star * *}$ & -0.000459 & $0.00323^{\star * *}$ & $0.00297^{\star * *}$ & $0.00644^{* * *}$ & $0.00575^{* * *}$ & $0.0226^{* * *}$ & $0.0148^{* * *}$ \\
\hline & $(0.000581)$ & $(0.00159)$ & $(0.000387)$ & $(0.000950)$ & $(0.000412)$ & $(0.000900)$ & $(0.000716)$ & $(0.00110)$ & $(0.00236)$ & $(0.00243)$ \\
\hline \multirow{2}{*}{ Cienc } & $-0.000674^{\star *}$ & -0.000378 & 0.000153 & $-0.00155^{\star \star \star}$ & $0.000435^{\star * *}$ & -0.000741 & $0.000968^{* * *}$ & 0.000375 & $0.00401^{* * *}$ & 0.00199 \\
\hline & $(0.000267)$ & $(0.000938)$ & $(9.76 \mathrm{e}-05)$ & $(0.000574)$ & $(0.000158)$ & $(0.000542)$ & $(0.000327)$ & $(0.000654)$ & $(0.00132)$ & $(0.00142)$ \\
\hline \multirow{2}{*}{$\mathrm{Tec}$} & $0.000906^{* * *}$ & -0.00180 & $0.00105^{\star * *}$ & 0.000349 & $0.00140^{\star * *}$ & $0.00470^{* * *}$ & $0.00212^{\star * *}$ & $0.0108^{\star * *}$ & $0.00573^{\star * *}$ & $0.0239^{* * *}$ \\
\hline & $(0.000297)$ & $(0.00181)$ & $(0.000263)$ & $(0.00110)$ & $(0.000328)$ & $(0.00106)$ & $(0.000488)$ & $(0.00131)$ & $(0.00131)$ & $(0.00283)$ \\
\hline \multicolumn{11}{|c|}{ Coeficientes gerais } \\
\hline \multirow{2}{*}{ Homens } & \multicolumn{2}{|c|}{$0.297^{\star \star *}$} & \multicolumn{2}{|c|}{$0.615^{\star * *}$} & \multicolumn{2}{|c|}{$0.830^{\star * *}$} & \multicolumn{2}{|c|}{$1.092^{\star * *}$} & \multicolumn{2}{|c|}{$1.605^{\star * *}$} \\
\hline & \multicolumn{2}{|c|}{$(0.00561)$} & \multicolumn{2}{|c|}{$(0.00383)$} & \multicolumn{2}{|c|}{$(0.00397)$} & $(0.00$ & 478) & $(0.01$ & 000) \\
\hline & 0.272 & $2^{* * *}$ & 0.56 & $* * *$ & 0.74 & $; * * *$ & $0.90 \varsigma$ & **** & $1.25 \mathrm{~S}$ & *** \\
\hline Mulheres & $(0.005$ & 511) & $(0.00$ & 04) & $(0.00$ & 255) & $(0.00$ & 307) & $(0.00$ & 698) \\
\hline Diferenças & 0.025 & $0^{* * *}$ & 0.049 & $2^{* * *}$ & 0.085 & $1^{* * *}$ & 0.183 & **** & 0.346 & $5^{* * *}$ \\
\hline Totais & $(0.007$ & 759) & $(0.00$ & 189) & $(0.00$ & 471) & $(0.00$ & 569) & $(0.01$ & 22) \\
\hline & -0.088 & $39^{* * *}$ & -0.08 & $2^{\star * *}$ & -0.06 & $5^{* * *}$ & -0.062 & $7^{* * *}$ & -0.073 & $4^{* * *}$ \\
\hline LApticalias & $(0.003$ & 365) & $(0.00$ & 61) & $(0.00$ & 215) & $(0.00$ & 248) & $(0.00$ & 564) \\
\hline Não & 0.114 & $4^{* * *}$ & 0.13 & & 0.15 & $* * * *$ & 0.246 & $5 * * *$ & 0.419 & **** \\
\hline explicadas & $(0.007$ & 764) & $(0.00$ & 64) & $(0.00$ & 146) & $(0.00$ & 540) & $(0.01$ & 16) \\
\hline & 0.06 & & -0.15 & $5 * * *$ & -0.35 & $0^{* * *}$ & -0.28 & $0^{* * *}$ & -0.26 & $5^{\star * *}$ \\
\hline Constante & $(0.05$ & 558) & $(0.0$ & & $(0.03$ & 27) & $(0.03$ & 95) & $(0.08$ & 52) \\
\hline Observações & 44,9 & & 44, & & 44, & & 44,9 & 72 & 44,9 & 72 \\
\hline
\end{tabular}

Desvios-padrão em parênteses

$* * * p<0.01, * * p<0.05, * p<0.1$ 
ANEXO

Anexo 1 - Subsetores da indústria de transformação

QUADRO A.1 SUBSETORES DA INDÚSTRIA DE TRANSFORMAÇÃO DE ACORDO COM A CNAE POR ATIVIDADE

Fabricação de alimentos e bebidas

Fabricação de Fumo

Fabricação de produtos têxteis

Confecção de artigos de vestuário e acessórios

Preparação de couros e fabricação de artigos de couro, artigos para viagem e calçados

Fabricação de produtos de madeira

Fabricação de celulose, papel e produtos de papel

Impressão e reprodução de gravações

Fabricação de coque, de produtos derivados de petróleo e de biocombustíveis

Fabricação de produtos químicos

Fabricação de produtos de borracha e produtos de plásticos

Fabricação de produtos minerais não-metálicos

Metalurgia

Fabricação de produtos de metal, exceto máquinas e equipamentos

Fabricação de máquinas e equipamentos

Fabricação de máquinas para escritórios e equipamentos de informática

Fabricação de máquinas, aparelhos e materiais elétricos

Fabricação de veículos automotores, reboques e carrocerias

Fabricação de outros equipamentos de transporte

Fabricação de móveis e indústrias diversas 